"This is the peer reviewed version of the following article: Oman S, Nagode M. The influence of piston shape on air-spring fatigue life. Fatigue Fract Eng Mater Struct. 2018; 41:1019-1031., which has been published in final form at https://doi.org/10.1111/ffe.12748. This article may be used for non-commercial purposes in accordance with Wiley Terms and Conditions for Use of Self-Archived Versions."

\title{
The influence of piston shape on air-spring fatigue life
}

\section{S. Oman*, M. Nagode}

University of Ljubljana, Faculty of Mechanical Engineering, Aškerčeva 6, SI-1000 Ljubljana, Slovenia Corresponding author: Tel.: +386 14771506. E-mail address: simon.oman@fs.uni-lj.si (S. Oman).

\section{Abstract:}

This paper presents how the piston shape of an air-spring can influence both its load-deflection characteristic and the fatigue life. Two piston shapes are considered in this study for which loaddeflection characteristics and fatigue lives are compared. A method for the estimation of air-spring fatigue life is upgraded by adding the influence of the mean stress level and afterwards used together with finite element analysis to predict the fatigue life, and ultimately the timing and global location of failure within the air-spring. These predictions are then compared with measured results and show good agreement thus proving the validity of the method used here for calculating fatigue life. Both experimental and predicted results show that the highest fatigue life can be expected if a noncylindrical, back tapered piston is used. This is only the case if the air-spring is mounted at its optimal design height as the study also shows that moving away from optimal design height does have a detrimental effect on the fatigue life of back tapered air springs. This is due to the appearance of higher stress amplitudes in the flex member during operation. Such stress amplitudes and consequently fatigue damage can be reduced by avoiding sharp transitions in the piston design that cause additional bending of the flex member in a direction opposite to the deflection in the flex member fold.

Keywords: Air-spring; Fatigue life; Fatigue testing; Critical plane approach; Finite element analysis

$\begin{array}{ll}\text { Nomenclature: } F_{E F} & \text { effective force of the air-spring } \\ p & \text { pressure inside the air-spring } \\ A_{E F} & \text { effective surface area of the air-spring } \\ D_{E F} & \text { effective diameter of the flex member } \\ D_{I N} & \text { inner diameter of the flex member } \\ D_{\text {OUT }} & \text { outer diameter of the flex member } \\ \sigma_{e q} & \text { equivalent stress } \\ \sigma_{a} & \text { stress amplitude } \\ \sigma_{m} & \text { mean stress } \\ \alpha & \text { mean stress sensitivity parameter } \\ H_{d h} & \text { design height of air-spring } \\ H_{\text {max }} & \text { maximum height of air-spring } \\ H_{\text {min }} & \text { minimum height of air-spring } \\ H_{\text {free }} & \text { free standing height of air-spring } \\ t_{c} & \text { thickness of the flex member } \\ \beta & \text { initial cord angle of the flex member } \\ p_{d h} & \text { pressure inside the air-spring at design height } \\ L_{a} & \text { load amplitude of air-springs } \\ r & \text { radius of loading of air-springs } \\ N & \text { number of cycles to failure } \\ \sigma_{i j} & \text { stress tensor } \\ n & \text { plane normal } \\ S_{n} & \text { stress vector of the selected plane } \\ N_{s} & \text { normal stress vector of the selected plane } \\ T_{s} & \text { tangential stress vector of the selected plane } \\ t & \text { time } \\ D_{i} & \text { calculated damage for it load cycle } \\ N_{i} & \text { number of cycles to failure for it load cycle } \\ n_{i} & \text { number of equal load cycles }\end{array}$




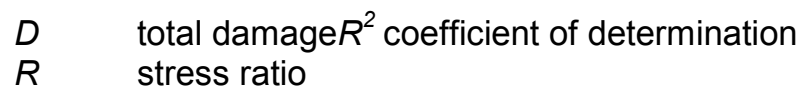

\section{Introduction}

Air-springs have been used in the suspension systems of commercial vehicles for many years and are now increasingly being incorporated into the design of passenger cars. This is due to certain advantages over conventional suspension systems, including increased driving comfort, height regulation possibility and adjustable rigidity. Such advantages are the result of the structure of the airspring, which allows the entire weight of the vehicle body to be transmitted to the wheels via compressed air trapped inside a flex member and the fact that the air pressure can be regulated. In general two different types of air-spring are in use: bellows or convolute air-springs; and rolling lobe air-springs (Figure 1). Only the rolling lobe air-spring contains a piston which serves as a support onto which the flex member is rolled during operation. The rolling lobe air-spring is composed of numerous elements that connect the flex member into a final product and provide it with functionality (Figure 2).

Due to the poor lateral stability of an air-spring, the vehicle body and chassis need to be mechanically linked to ensure the stability of the vehicle in the transverse direction so that the air-spring is only loaded in its axial direction (usually the movement of the piston is guided by a mechanical connection after a certain radius). In the initial static state, the air-spring is filled with compressed air to a pressure that provides the desired height of the vehicle (the position of the air-spring at this particular height is called the design height). The air-spring starts to work as the piston moves. Due to the piston movement, the volume of the compressed air changes. Consequently the pressure and the axial force (also known as the effective or operating force) changes too. This is the "spring" action. How the volume and pressure of the air-spring change in relation to the displacement of the piston depends primarily on the piston shape, the flex member properties and geometry and the gas inside the airspring. Therefore by changing the shape of the piston, the load-deflection characteristic of the airspring also changes. In order to provide the desired load-deflection characteristic, developers are often forced to adjust the piston shape for each application. Field measurements have shown that changing the piston shape also affects the air-spring fatigue life. Therefore designers need to pay attention to two objectives when designing the piston. First the air-spring load-deflection characteristic must be optimised and second, fatigue life must be maximised. In this article the influence of the piston shape on air-spring fatigue life is considered. To do this, a model for calculating air-spring fatigue life based on accelerated experiments has been applied ${ }^{1,4}$. As a part of this study, the basic method has been upgraded by adding the influence of the mean stress level on air-spring fatigue life. In the conclusion some guidelines for the design of the pistons are provided together with optimal geometries for air-springs with an increased fatigue life.

\section{Influence of piston shape on air-spring load-deflection characteristic}

The development of air-springs is a procedure that is entirely controlled by the specific application for which the air-spring is designed. Initially the following specifications will be known: maximum and minimum height, pressure range, maximum diameter, required load capacity and pressure at a specific height. To accommodate these specifications the shape and composition of the flex member and the geometry of a piston and a bead plate should be designed based on analytical calculations or numerical simulations. The effective force produced by an air-spring is dependent on the product of pressure and the effective surface area ${ }^{1,2}$ and can be calculated using Equation 1

$$
F_{E F}=p \cdot A_{E F}=p \cdot \frac{\pi \cdot D_{E F}}{4}
$$

where $p$ is the pressure inside the air-spring, $A_{E F}$ is the effective surface area and $D_{E F}$ is the effective diameter of the flex member (Figure 3).

During operation, the air-spring responds to different driving conditions by changing its height in order to reduce the shock impulse. As a result of such height changes, the pressure inside the air-spring and the effective diameter at any particular location change. How these two parameters change in relation to the air-spring height very much depends on the piston shape. For example the piston shape can be varied to achieve a constant spring rate (the rate between the effective force and the piston movement) for normal driving conditions, whilst for off road use an increased spring rate at the end of the air-spring's stroke assures a more comfortable ride most of the time, whilst reducing the effects of high impacts in extreme driving conditions. Two different piston shapes are considered in this research to show the influence of piston shape on air-spring load-deflection characteristic and fatigue life (Figure 4). The first piston has a cylindrical shape, and is the most basic form of piston (Figure 4 left). The second piston, usually called a back tapered piston, has a concavity or recess on the 
cylinder wall in order to reduce the air-spring stiffness at a specific air-spring height (Figure 4 - right). All other components used in the air-spring assemblies remain the same in order to assess the affect of changing the piston shape only.

Measured dependence of the effective force on the height of the air-spring and on the piston shape is shown in Figure 5. Measurements are made on a servo-hydraulic test rig using a design height of 260 $\mathrm{mm}$ with a corresponding pressure of 7 bar. For static measurements the pressure is kept constant and for dynamic measurements the air-spring is sealed after an initial pressure of 7 bar is reached at the design height. What is interesting here is that the shape of the piston is reflected in the graph of static air-spring load-deflection characteristics (Figure 5). The piston shape is only visible from the part of the curve where the flex member is rolled over the piston (from the lower position to approximately $330 \mathrm{~mm}$ ). This is because the effective force is dependent on the pressure and the effective diameter of the flex member and the fact that in the field of rolling of the flex member over the piston, the effective diameter changes together with the piston diameter. A larger piston diameter means a larger effective diameter and vice versa. As pressure is kept constant during static load-deflection characteristic measurements the only variable is the effective diameter. Therefore, the graph of effective force vs. air-spring height (Figure 5) takes the shape of the piston. The air-spring spring rate during compression in general increases if a tapered piston (i.e. a piston with a larger diameter at the bottom) is used and decreases or is constant when a back tapered piston is used.

\section{Flex member damage mechanism}

The flex member is made from a fibre reinforced rubber composite material. Two layers of rubber bands and two layers of ply compound (composed from parallel nylon threads in a rubber matrix) are wound onto a production valve, starting and finishing with rubber band layers. The first rubber band layer is called the liner and the second is referred to as the cover. The ply compound has to be placed in such a way that the nylon threads form a mesh that is symmetrical on the flex member axis. This composite structure is then referred to as a blank. Once the layers are stuck to each other, the blank is removed from the production valve, inserted into a mould and cured using water vapour to achieve both the final desired shape and improved adhesion between the individual layers. Previous research $^{3-5}$ and experience from the field shows that damage of the air-spring flex member starts to emerge at the connection between the liner and the inner ply compound. This region is the most critical due to the appearance of the largest stress-strain amplitudes here and the fact that the bond between the different layers is not as strong as the strength of the rubber material from which the liner is formed. The stress-strain state of the flex member changes from tensile to compression and vice versa due to the air-spring principle of operation ${ }^{5}$. In addition to normal stresses, both shear and torsional stresses occur mostly in the rubber between both layers of ply compound due to the changes in cord angle ${ }^{1}$. The critical plane where visible cracks appear is usually perpendicular to the air-spring axis which indicates that normal stresses are critical for the flex member at its most critical location (connection between the liner and the inner ply compound). The highest compression stress on this plane appears when the observation point is located on the largest diameter and the largest tensile stress appears when the observation point is located on the smallest diameter of the flex member. Such a change of the stress state at the observation point is due to the change of the cord angle ${ }^{1}$, which depends on the diameter of the flex member at the location of the observation point. In addition, a further bending load appears when the observation point is located on the fold of the flex member. This causes additional changes in local stress-strain state. Due to the rolling of the flex member, the stress-strain state of the observation (critical) point constantly changes which eventually leads to the fatigue crack formation. The crack is initially invisible because, as mentioned above, it occurs at the interface between the liner and the ply compound, but eventually the crack grows through the liner and becomes visible, therefore allowing leakage of air from the air-spring interior out through the nylon threads. From this point onward the crack grows and the leakage increases. If use of the air-spring is continued a partial delamination of the liner and the ply compound can occur which may result in a complete collapse of the flex member.

\section{Simulation of the air-spring by finite element analysis}

\subsection{The finite element model}

As the stress-strain state inside the flex member is the main point of interest in this study, the flex member should be modelled in a way that allows a realistic air-spring response in the finite element (FE) model whilst other parts can be reasonably simplified. Hence the bead plate (Figure 2) and piston are modelled as standard shell rigid elements of the type R3D4. The flex member is modelled as a homogeneous shell with two rebar layers that are used to simulate the reinforcement layers (ply compound $)^{6}$. Rebar layers are exactly defined by area per bar, spacing between bars, orientation 
angle, position and material properties (Figure 6). To model the flex member, standard shell elements of type S4R are used. The method used for modelling the flex member does not allow for a fully accurate analysis of the stress-strain state by individual layers of the composite, but only a list of the stress-strain state on the surface or in reinforcing fibers. Although our previous research ${ }^{3-5}$ and experience from the field shows that damage of the air-spring flex member starts to emerge at the connection between the liner and the inner ply compound, the selected method is suitable for determining a global critical location and value of the flex member damage. This is due to the fact that stress amplitudes at the connection between the liner and the inner ply are in a very good correlation with the stress amplitudes at the inner ply surface ${ }^{1,3-5}$.

The key factor for the operation of an air-spring is the air trapped inside the flex member. To simulate the operation of an air-spring the air also needs to be modelled. Air inside the air-spring is modelled by a surface-based fluid cavity with adiabatic behaviour. Adiabatic behaviour can be used since those losses during operation that could influence the heat change are small, therefore the heat produced during one load cycle is negligible.

The material properties of the rubber (used in the liner and cover layers, and the matrix material of the ply compound layers), and nylon (cord) threads (used as the reinforcement of the ply compound) were obtained by simple tension and compression tests ${ }^{3,7,8}$. As both of these materials exhibit hyperelastic material characteristics, a hyperelastic material model with a three parametric Ogden formulation ${ }^{9}$ is used. The parameters for the Ogden material model are obtained by fitting the model to the simple tension and compression test results. Although cord threads, due to their structure, have anisotropic properties, Ogden material model (isotropic material model) can be used since cord threads are modelled as a uniaxial rebar layer that can carry only axial loads. No other than axial stress-strain component exist in rebar element. Therefore it does not make any difference if the rebar material is defined as isotropic or anisotropic material.

Contacts are modelled as surface-to-surface contact pairs in the contact region (see Figure 7). The contact is modelled as a penalty contact with a friction coefficient of 0.3 in the tangential direction and a hard contact in the normal direction. The simulation is carried out using 4 load steps. In the first load step, the model is loaded with some pressure to obtain the inflated shape of the bellows. In the second load step the piston is moved all the way to reach the air-spring design height position. In the third and fourth load case the piston is moved for $\pm 50 \mathrm{~mm}$ to reach the lower and upper testing position respectively. In order to compare the FE analysis results with experimental measurements, two types of piston movement are simulated using FE analysis. First the piston is moved only in an axial direction to compare the FE analysis with basic experimental measurements so as to obtain a comparable air-spring load-deflection characteristic. Second the piston is moved along a circular path with a radius of $1200 \mathrm{~mm}$ to simulate the more realistic conditions used in the fatigue measurements.

\subsection{FE analysis verification}

To verify the FE analysis, measured and simulated load-deflection characteristics of the air-spring are compared. A comparison of the effective force and pressure between the measured data and the results gained by the FE simulation is shown in Figure 8 . The comparison is made for 7 bar of pressure at the design height position. It is evident from Figure 8 that both the operating force and pressure gained with the simulation demonstrates very good agreement with the measured data. Therefore all the data gained using FE analysis here are considered useful for subsequent use in fatigue damage prediction.

\subsection{FE analysis results}

The analysis shows that the most critical plane, where normal stress amplitudes are the highest, for both shapes of piston is the plane perpendicular to the air-spring axis (the X-plane). This was expected since most of the visible cracks that have occurred during fatigue measurements lie in the same plane and the fact that the direction of the crack plane is usually normal to the direction of the maximum stress ${ }^{6}$. The stress-strain results for different piston shapes show that the shape of the piston strongly affects the stress-strain response of the flex member (Figure 10) and in addition to the normal stresses, the position of maximum stress amplitude changes. Position of maximum stress amplitude mostly depends on used design height, but also depends on the piston shape which is evident when comparing Figures $10 \mathrm{D}$ and $10 \mathrm{H}$. In any case the position of maximum stress amplitude does not change significantly because it is always located at the point that passes through the fold from a larger to a smaller diameter of the flex member. It is obvious from Figure 9 that the maximum stress appears on the radius between the horizontal and the vertical part of the piston. This stress is mainly the result of bending of the flex member over the piston. It is more or less static stress since it 
does not change much during air-spring operation. Therefore this area of the flex member is not critical for fatigue damage. To find the part of the flex member where fatigue damage is critical, the point with the largest change in stress during operation should be located. For the case shown in Figure 9 the most critical area of the flex member is where the flex member rests at the lowest piston diameter. For the back tapered piston, the location of the most critical point of the flex member is also dependant on the design height. This research shows that for the back tapered piston, the design height is the most important parameter in terms of its impact on fatigue life and as such should be carefully chosen in order to increase the fatigue life. How the stress amplitude varies with the position on the flex member for different design heights and different piston shapes can be seen from Figure 10. These amplitudes are shown for one vertical line of nodes where the stress amplitudes are the highest.

\section{Calculation of the flex member fatigue life}

\subsection{Method used for the estimation of the flex member fatigue life}

The fatigue life of the flex member is calculated using a method for the estimation of air-spring fatigue life based on accelerated experiments (experiments with constant load amplitude that last up to two million cycles until critical damage appears) ${ }^{4,5}$. The method uses crack nucleation approach that is based on quantities that are defined at a material point, in the sense of continuum mechanics ${ }^{10-11}$. Different predictors like maximum stretch ratio ${ }^{12}$, maximum principal Cauchy stress ${ }^{13,14}$, strain energy density ${ }^{13,15}$, cracking energy density ${ }^{16}$ and others ${ }^{17,18}$ has been used to predict a fatigue crack nucleation. To predict the fatigue life of an air-spring, simple critical plane approach using Cauchy stress tensor as an input proved to be a successful method ${ }^{4,5,19-21}$. As a part of this study, the basic method has been upgraded by adding the influence of the mean stress level on air-spring fatigue life. The damage parameter used for calculation of the flex member fatigue life is therefore the equivalent stress that appears on the flex member during operation. Basically, the method consists of two parts. In the first part, the durability curve of the air-spring is formed (Figure 11) combining the results of performed accelerated experiments (Figure 11A) and simulations of these same experiments with FE analysis (Figure 11B) from which equivalent stresses can be calculated. The durability curve is formed for the most critical point of the flex-member where critical damage appears. Experiments on at least two different load levels have to be performed to form the durability curve. The research shows that it is best to vary the initial pressure inside the air-spring since this parameter has the highest impact on the maximum equivalent stress. Stress amplitudes and mean stresses are then calculated for each node of the flex member (Figure 11B) by converting the averaged stress tensors to uniaxial normal stresses using the critical plane approach. Equivalent stress for each node is then calculated using a mean stress sensitivity parameter in the form ${ }^{22-24}$ :

$$
\sigma_{e q}=\sigma_{a}+\alpha \cdot \sigma_{m} ; 0 \leq \alpha \leq 1
$$

where $\sigma_{e q}$ is equivalent stress, $\sigma_{q}$ stress amplitude, $\sigma_{m}$ mean stress and $\alpha$ mean stress sensitivity parameter. Mean stress sensitivity parameter controls the influence of mean stress effect on fatigue life. It can vary between 0 (the effect of mean stress is excluded from calculation) and 1 (mean stress has the same effect on fatigue life as stress amplitude). The effect of mean stress is adjusted with respect to material response at different mean stress values. For the purpose of this study mean stress sensitivity parameter $\alpha$ has been determined on the basis of the minimum deviation (maximum $R^{225}$ ) of the durability curve from the five points that define it (Figure 13). These five points are gained by combining equivalent stresses at the most critical point of the flex-member for different load cases with the number of cycles to failure gained by accelerated experiments. It turns out that for presented case the optimal value is $\alpha=0$. It is necessary to note that the value of mean stress sensitivity parameter $\alpha$ has been determined on the basis of five critical points where stress ratio $R$ is not much different (from -6.4 to -7.7). This means that due to the scattering the calculated value of mean stress sensitivity parameter $\alpha$ is not necessary the correct one. Despite the questionable value of mean stress sensitivity parameter $\alpha$, the damage and the fatigue life calculations for the flex member critical region is entirely appropriate since the stress ratio $R$ for this region is practically equal to the stress ratio $R$ for which the durability curve is determined. The resulting durability curve belongs to the flex member with a given composition. This means that the same durability curve is valid for air-springs where the same flex member is used or at least the flex member has the same composition (matrix material and its thickness, cord material and its position, area per bar and spacing between bars). In the second part of the method, fatigue life can be calculated for different loading conditions or different geometries using known durability curve, FE analysis, conversion of stress tensors to equivalent stresses and the selected damage accumulation rule (Figure 12). For the purpose of this study Miner 
damage accumulation rule ${ }^{26}$ has been used to calculate the total damage. The absolute accuracy of the air-spring fatigue life predictions largely depends on the durability curve obtained on the basis of accelerated tests. Therefore special attention is required when defining the frequency of accelerated tests to prevent heating of the flex member beyond its normal use.

\subsection{Durability curve determination}

Durability curve is determined on the basis of previously performed ${ }^{4,5}$ accelerated experiments for six different loading conditions that are described in Table 1. Two different FE analyses (two different pressures at the design height position) are performed from which the needed stress tensors and equivalent stresses are gained. Results of the calculated equivalent stresses for associated loading conditions are presented in Table 2. Combining the simulations (stress amplitude) and tests (number of cycles to failure) results, the durability curve is created for a $50 \%$ probability of air-spring failure (Figure 13). It is necessary to emphasize that the flex members used for accelerated experiments were subjected to an artificial ageing process in order to reduce the fatigue life4. Therefore, predicted fatigue lives include this information and are not directly comparable to the use in exploitation by absolute value. Assuming that the slope of the durability curve due to artificial ageing does not change essentially, such a curve can only be used for relative comparison of various effects on air springs fatigue life. This is the reason why results in Table 3 and Table 4 are shown in relative form that directly indicates how great the influence of the piston shape on fatigue life is.

\subsection{Calculated damage of the flex member for different design heights and piston geometries}

The calculated damage for different cases is shown in Figure 14. The damage for all cases is calculated for the same number of cycles. The number of cycles is chosen in such a way that the maximum damage for a back tapered piston with a design height of $260 \mathrm{~mm}$ is 1 . Comparing Figures $14 \mathrm{D}$ and $14 \mathrm{H}$ it is obvious that the damage of the flex member is dependent on the piston shape. Further, if the area of the piston over which the flex member is rolled is not cylindrical the flex member damage is dependent on the design height too. As seen from Figures $14 \mathrm{~A}$ to $14 \mathrm{~F}$ an optimum design height of approximately $260 \mathrm{~mm}$ gives the maximum fatigue life. If the design height is either increased or decreased the fatigue life of the air-spring is reduced. Furthermore, changes in the design height give rise to changes in the critical location. This is due to the fact that the back tapered piston has small radii on the transition from a straight to concave profile which causes additional bending of the flex member and consequently an increase in tensional stresses on its inner side. This causes the transition from pulsating to alternating bending loads of the flex member, which drastically reduce the service life. When the optimal design height of $260 \mathrm{~mm}$ is used the flex member does not come into the contact with the lower transition radius and does not leave the upper transition radius during operation. Therefore these two radii do not have any influence on the flex member fatigue life. If the design height is reduced the flex member comes into contact with the lower transition radius only for a short time during the whole loading cycle. This causes an increase in the stress amplitude and consequently an increase in damage. Similarly, if the design height is increased, the flex member at some point leaves the upper transition radius and the result is the same. Therefore the critical point of the flex member is located on the place that is in contact with the lower piston transition radius when design heights smaller or equal to $250 \mathrm{~mm}$ are used or on the place that is in contact with the upper piston transition radius when design heights bigger or equal to $275 \mathrm{~mm}$ are used. For design heights between $250 \mathrm{~mm}$ and $275 \mathrm{~mm}$, the critical point is located where the concave profile of the piston has the smallest diameter.

In summary, greater fatigue life of the air-spring can be obtained if the back tapered piston is used instead of the straight one. Namely, back tapered piston, because of its smaller diameter in the recess region, provides bigger radius of the flex member fold and consequently lower stress amplitudes and therefore higher fatigue life. This is only the case if the optimum design height $(260 \mathrm{~mm})$ is used and assumes that load cycles are not greater than the considered $\pm 50 \mathrm{~mm}$ which prevents the influence of the transition radii of the back tapered piston on the flex member fatigue life. Otherwise the back tapered piston suffers much higher damage compared to that calculated for the straight piston.

\section{Experimental section}

\subsection{Tested air-spring}

The air-spring studied here is an air-spring used for suspension of a bus. Construction of this airspring is common for a rolling lobe air-spring. Therefore it consists of a piston, which in this case also 
provides an additional volume of the air-spring, a flex member and a bead plate. For the purpose of this research, two different air-spring systems using different piston shapes (straight and back-tapered Fig. 4) with the same maximum diameter of $205 \mathrm{~mm}$ has been tested. For both air-spring systems, the same flex member geometry has been used. Both air-spring systems have the following specifications:

- recommended design height: $H_{d h}=260 \mathrm{~mm}$

- maximum height: $H_{\max }=500 \mathrm{~mm}$

- minimum height: $H_{\min }=200 \mathrm{~mm}$

- free standing height: $H_{\text {free }}=562 \mathrm{~mm}$

- flex member thickness: $t_{c}=4.5 \mathrm{~mm}$

- initial flex member cord angle: $37^{\circ}<\beta<46^{\circ}$ (depends on the position since outside diameter is not constant)

\subsection{Fatigue experiments}

All experiments are made by using a test rig $^{27}$ specially designed for air-springs. The test rig has the possibility of simulating the realistic movement of the air-spring whereby the piston is not moved directly in the air-spring axis direction, but along a circular path with a manually adjustable radius (from 900 to $1500 \mathrm{~mm}$ ). For this research, the radius was set to $1200 \mathrm{~mm}$ which corresponds to the kinematics of the bus chassis on which this particular air-spring is used. This same mounting geometry is also used for the FE analyses. Loading of the air-springs is applied by symmetrical piston movement around the design height, and is set at $\pm 50 \mathrm{~mm}$. Measurements are carried out for the back tapered piston at two design heights and for the straight piston at one design height (Table 3). The critical damage criterion used in all the experiments is a 2 bar pressure drop that in most cases shows good correlation with visible damage of the flex member (e.g. cracks, blisters or delamination).

\section{Comparison of experimental results with the predicted values}

To be able to compare measured and predicted values of the fatigue life, the number of cycles leading to the critical damage $(D=1)$ for different cases has been calculated. These results are shown in Table 4 as a relative value with respect to the case where a back tapered piston with an optimum design height of $260 \mathrm{~mm}$ is used.

Comparing measured fatigue life (Table 3 ) with the predicted (calculated) fatigue life (Table 4) it is obvious that the predicted fatigue life correlates very well with the measurements. There are some minor deviations between measured and predicted values but all lie within the measuring scatter. Therefore, the experiments confirm those conclusions from Section 5 regarding the influence of the design height and piston shape on the air-spring fatigue life.

\section{Conclusions}

To achieve the required load-deflection characteristic of an air spring it is often necessary to adjust the geometry of the piston. In practice, it has been shown that even small changes in the geometry of the piston can drastically affect the fatigue life of the air-spring which is confirmed with this research.

An improved model for the calculation of air-spring fatigue life based on accelerated experiments ${ }^{1,4}$ has been used to determine the influence of the piston shape on air-spring fatigue life. A comparison of the fatigue life of two differently shaped pistons: straight (cylindrical) and back tapered has been given here (Figure 4). The finite element results confirm the shape of the piston has a strong influence on air-spring fatigue life that was previously detected in field and laboratory experiments. Moreover, it is noted that the design height of the air-spring has a very strong impact on its fatigue life if the back tapered piston is used.

The following conclusions can be drawn:

- when the back tapered piston is used for an air-spring assembly, further attention is required to define the optimal design height in order to achieve maximum service life,

- by selecting the optimal design height, greater service life of the air-spring can be achieved using a back tapered piston as compared to a cylindrical piston, 
- sharp transitions causing bending of the flex member in the opposite direction of the deflection in the flex member fold should be avoided when designing the piston (otherwise alternating bending loads are applied to the flex member, which drastically reduce the service life).

This research has confirmed that piston shape influences the air-spring load-deflection characteristic and fatigue life. This is due to the type of bending applied to the flex member when different piston shapes are used. An alternating bending of the flex member occurs if a back tapered piston is used (except if design height from $260 \mathrm{~mm}$ to $270 \mathrm{~mm}$ is used which ensures that the flex member does not cross the lower transition radius nor leave the upper one which means that bending load is pulsating) compared to pulsating bending if a cylindrical piston is used. Furthermore, it has been shown that the model for the prediction of air-spring fatigue life can determine the influence of the piston shape or specified design height on the air-spring fatigue life in the early stages of development which will ultimately provide the possibility of faster and cheaper development of air-springs.

\section{Acknowledgements}

This research was supported by the Slovenian Research Agency. We would also like to show our gratitude to ContiTech for carrying out the experiments required for this study and for sharing their professional knowledge and experience with us during the course of this research.

\section{References}

1. Oman, S., Fajdiga, M. and Nagode, M. (2010) Estimation of air-spring life based on accelerated experiments. Mater Des, 31, 3859-3868

2. Rebernik, J. (2008) Development of Air-Spring optimization program. Faculty of mechanical engineering, University of Ljubljana.

3. Oman, S., Nagode, M. and Fajdiga, M. (2009) The material characterization of the air-spring bellows sealing layer. Mater Des, 30, 1141-1150

4. Oman, S. (2010) Model for estimation of air-spring life based on accelerated experiments. Faculty of mechanical engineering, University of Ljubljana.

5. Oman, S. and Nagode, M. (2013) On the influence of the cord angle on air-spring fatigue life. Eng Fail Anal, 27, 61-73

6. Previati, G. and Kaliske, M. (2012) Crack propagation in pneumatic tires: Continuum mechanics and fracture mechanics approaches. Int J Fatigue, 37, 69-78

7. ASTM standard. (2008) Practice for Rubber - Measurement of Dimensions. ASTM D3767

8. DIN standard. (2009) Determination of tensile stress/strain properties of rubber. DIN 53504

9. Ogden, R.W. (1972) Large Deformation Isotropic Elasticity - On the Correlation of Theory and Experiment for Incompressible Rubberlike Solids. Proceedings of the Royal Society of London. Series A, Mathematical and Physical Sciences, 326(1567), 565-584

10. Mars, W.V. and Fatemi, A. (2002) A literature survey on fatigue analysis approaches for rubber. Int J Fatigue, 24, 949-961

11. Mars, W.V. and Fatemi, A. (2005) Multiaxial fatigue of rubber: Part I: equivalence criteria and theoretical aspects. Fatigue Fract Eng Mater Struct, 28, 515-522

12. Cadwell, S.M., Merrill, R.A., Sloman, C.M. and Yost, F.L. (1940) Dynamic fatigue life of rubber. Rubber Chem Technol, 13, 304-315

13. Abraham, F., Alshuth, T. and Jerrams, S. (2005) The effect of minimum stress and stress amplitude on the fatigue life of non strain crystallising elastomers. Mater Des, 26, 239-245

14. Saintier,N., Cailletaud,G. and Piques, R. (2006) Crack nucleation and propagation under multiaxial fatigue in natural rubber. Int J Fatigue, 28, 61-72

15. Yeoh, O. H. (1993) Some Forms of the Strain Energy Function for Rubber. Rubber Chem Technol, 66, 754-771

16. Mars, W.V. (2002) Cracking energy density as a predictor of fatigue life under multiaxial conditions. Rubber Chem Technol, 75, 1-17

17. Verron, E. and Andriyana, A. (2008) Definition of a new predictor for multiaxial fatigue crack nucleation in rubber. J Mech Phys Solids, 56, 417-443 
18. Ayoub, G., Nait-Abdelaziz, M. and Zairi, F. (2014) Multiaxial fatigue life predictors for rubbers: Application of recent developments to a carbon-filled SBR. Int J Fatigue, 66, 168-176

19. Fatemi, A. and Socie, D.F. (1988) A critical plane approach to multiaxial fatigue damage including out-of-phase loading. Fatigue Fract Eng Mater Struct, 11, 149-165

20. Carpinteri, A., Spagnoli, A. and Vantadori, S. (2017) A review of multiaxial fatigue criteria for random variable amplitude loads. Fatigue Fract Eng Mater Struct, 40, 1007-1036

21. Chung, J. and Kim, N.H. (2016) Numerical methods of multiaxial fatigue life prediction for elastomers under variable amplitude loadings. Fatigue Fract Eng Mater Struct, 39, 866-876

22. Kujawski, D. and Ellyin, F. (1995) A unified approach to mean stress effect on fatigue threshold conditions. Int J Fatigue, 17,101-106

23. Shariati, M., Hatami, H., Yarahmadi, H. and Eipakchi, H. R. (2012) An experimental study on the ratcheting and fatigue behavior of polyacetal under uniaxial cyclic loading. Mater Des, 34, 302312

24. Mortazavian, S and Fatemi, A. (2016) Effects of mean stress and stress concentration on fatigue behavior of short fiber reinforced polymer composites. Fatigue Fract Eng Mater Struct, 39, 149166

25. Rice, J. A. (2007) Mathematical Statistic and Data Analysis 3rd Ed., University of California, Berkeley, Brooks/Cole, Cengage Learning

26. Miner, M.A. (1945) Cumulative Damage in Fatigue. J Appl Mech-T ASME,12, A159-164

27. Okorn, I., Oman, S., Nagode, M., Fajdiga, M. and Kramar, J. (2006) Stroj za preskušanje zračnih vzmeti AFT4. Faculty of mechanical engineering, University of Ljubljana 


\section{Captions for Figures and Tables}

Figure 1: A) Bellows and B) Rolling lobe air-springs

Figure 2: Detailed sketch of a rolling lobe air-spring

Figure 3: Cross section of an air-spring showing characteristic diameters

Figure 4: Piston shapes discussed in the text: left - straight, right - back tapered

Figure 5: Static and dynamic air-spring load-deflection characteristics for straight and back tapered pistons

Figure 6: Definition of the rebar layer

Figure 7: Details of the finite element model: A) Element types, B) Supports, C) Contacts and supports and D) Fluid cavity

Figure 8: Comparison of measured and simulated air-spring load-deflection characteristics

Figure 9: Analysis results (normal stresses on X-plane) at the inner side of the flex member for $A$ ) Lower air-spring position and B) Higher air-spring position

Figure 10: Calculated stress amplitudes vs. vertical position on the extended flex member for different design heights: A) $230 \mathrm{~mm}$, B) $240 \mathrm{~mm}$, C) $250 \mathrm{~mm}$, D) $260 \mathrm{~mm}$, E) $270 \mathrm{~mm}$, F) $280 \mathrm{~mm}$, G) $283 \mathrm{~mm}, \mathrm{H}) 290 \mathrm{~mm}, \mathrm{I}) 260 \mathrm{~mm}$ and different piston shapes: A-H) back tapered, I) straight

Figure 11: The process of defining the durability curve of the product

Figure 12: The process for the estimation of air-spring damage or fatigue life

Figure 13: Durability curve for $50 \%$ probability of air-spring failure

Figure 14: Calculated damage of the flex member for different design heights: A) $230 \mathrm{~mm}$, B) $240 \mathrm{~mm}$, C) $250 \mathrm{~mm}$, D) $260 \mathrm{~mm}$, E) $270 \mathrm{~mm}$, F) $283 \mathrm{~mm}$, G) $290 \mathrm{~mm}$, H) $260 \mathrm{~mm}$ and different piston shapes: A-G) back tapered, H) straight

Table 1: Fatigue test results for different loading conditions.

Table 2: Calculated equivalent stresses in the flex-member at the most critical location.

Table 3: Measured number of cycles to failure.

Table 4: Predicted number of cycles (relative value) to failure for different cases.
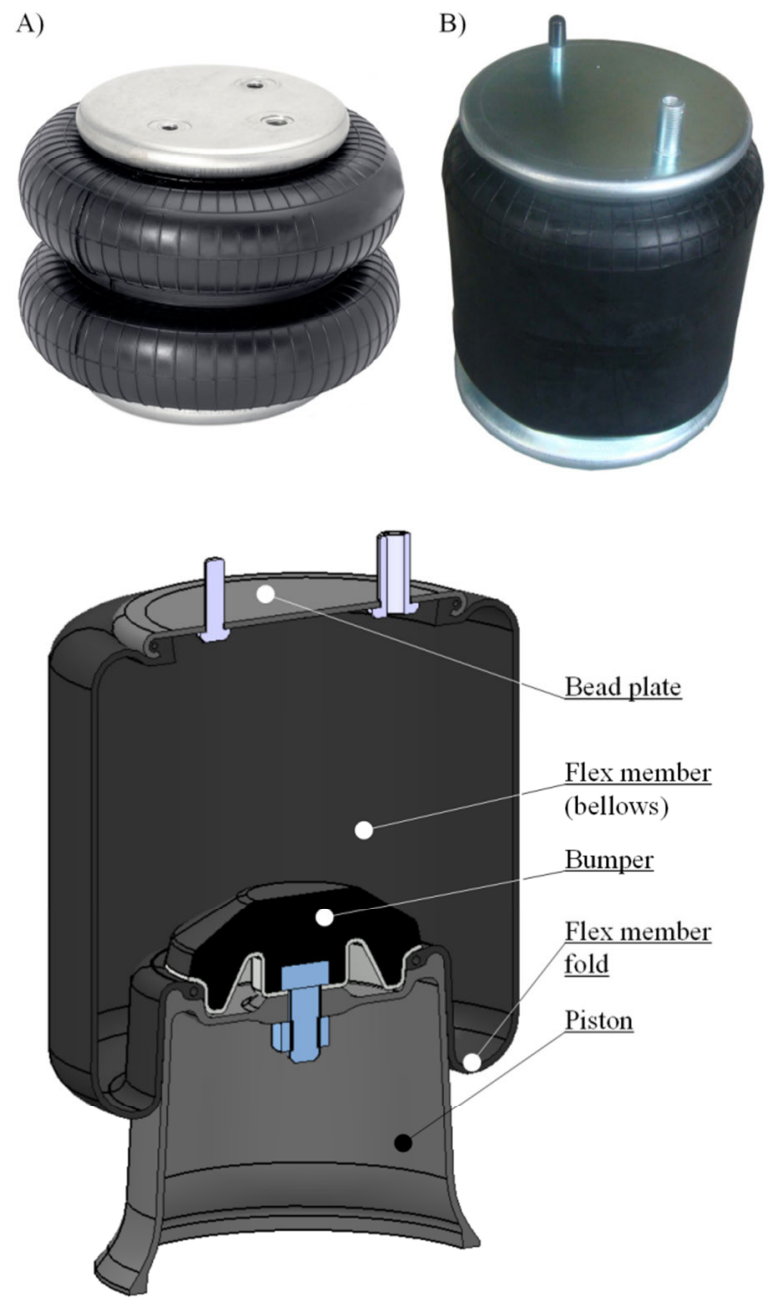

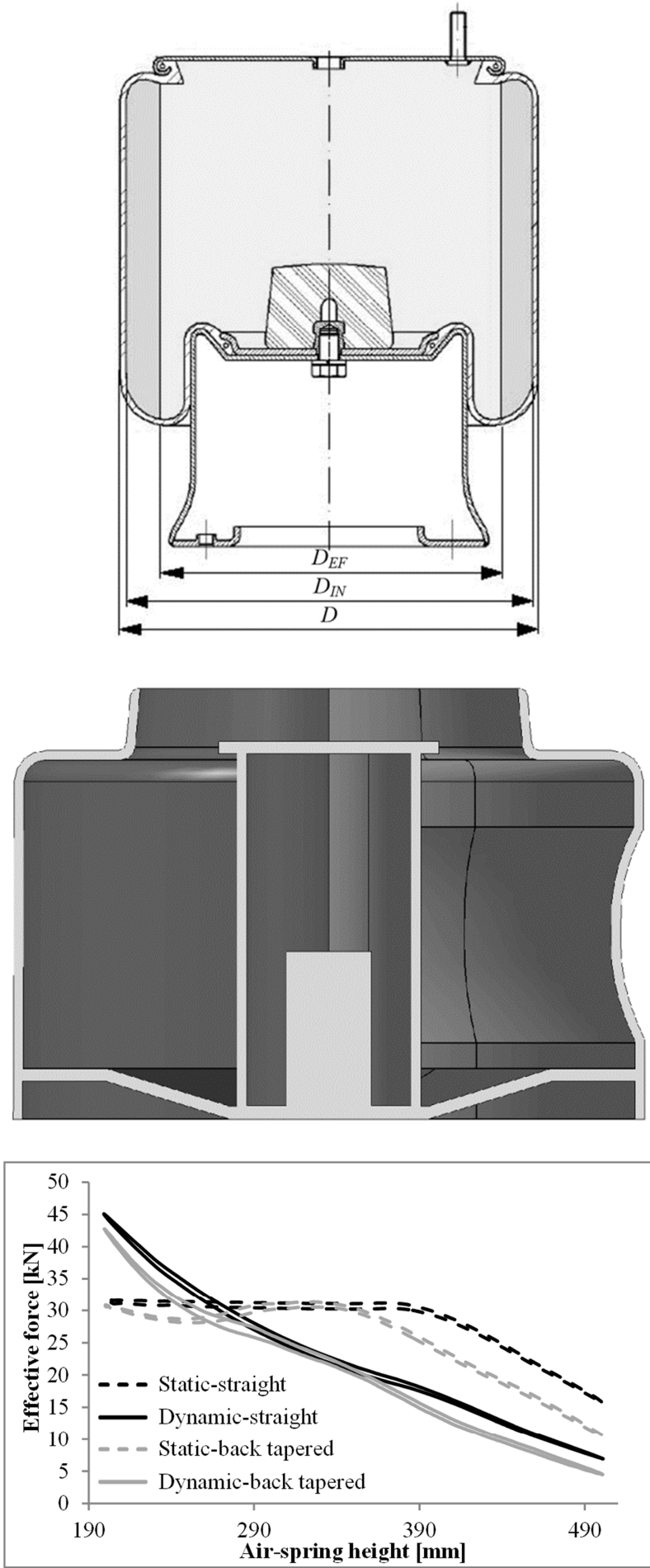

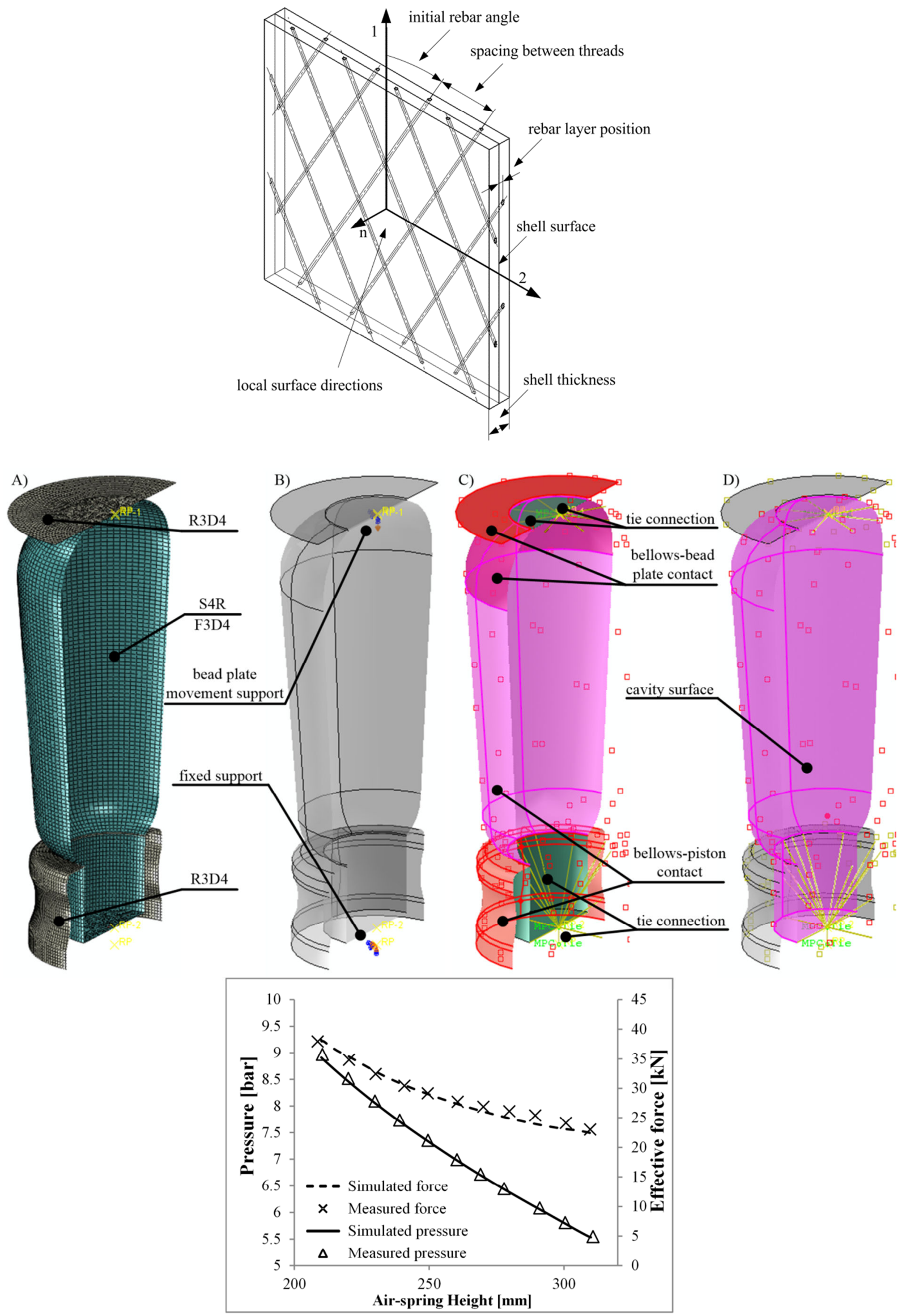

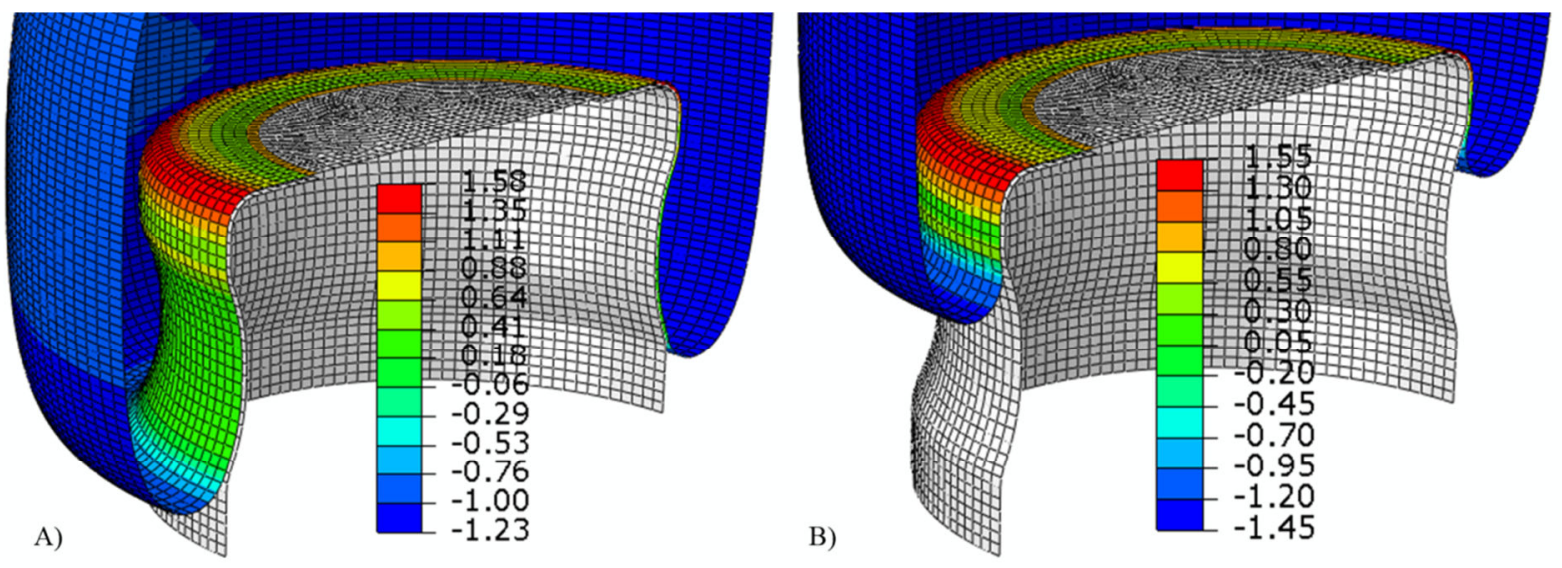
A)

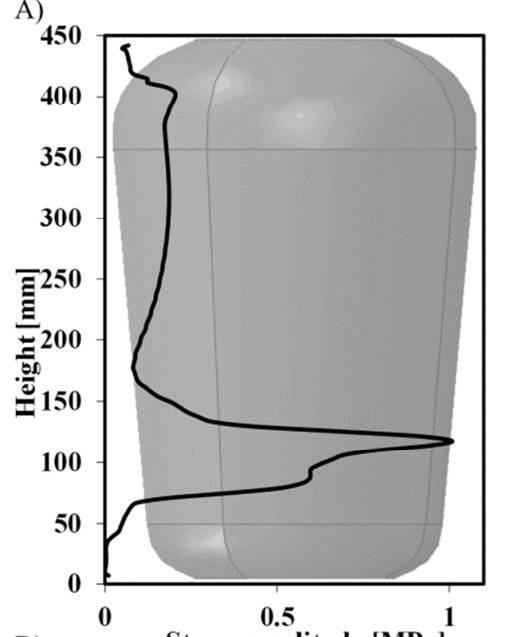

D)

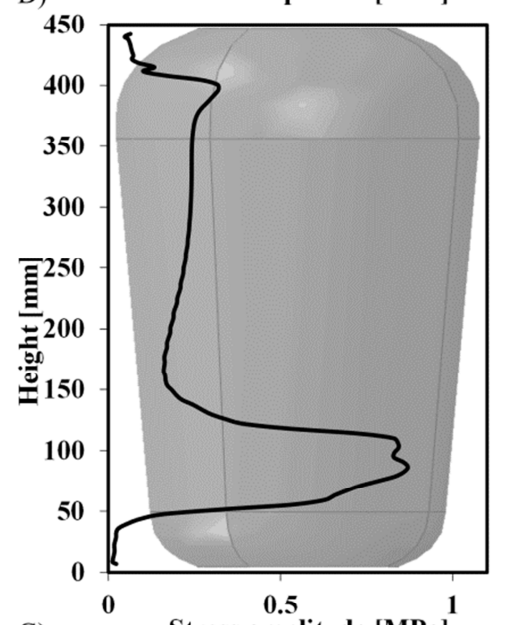

G)

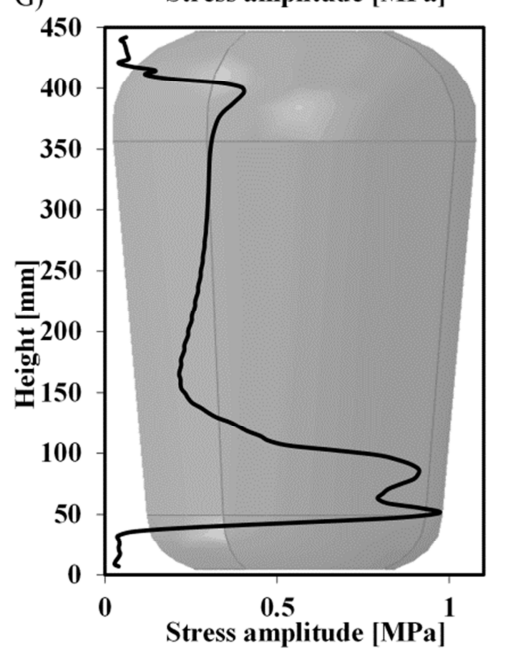

B)

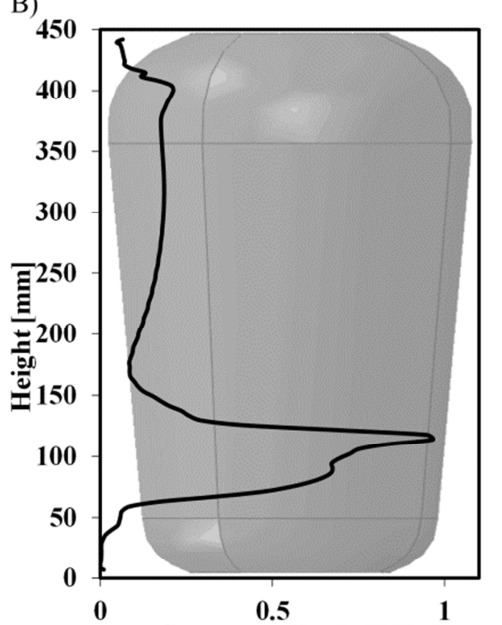

E)

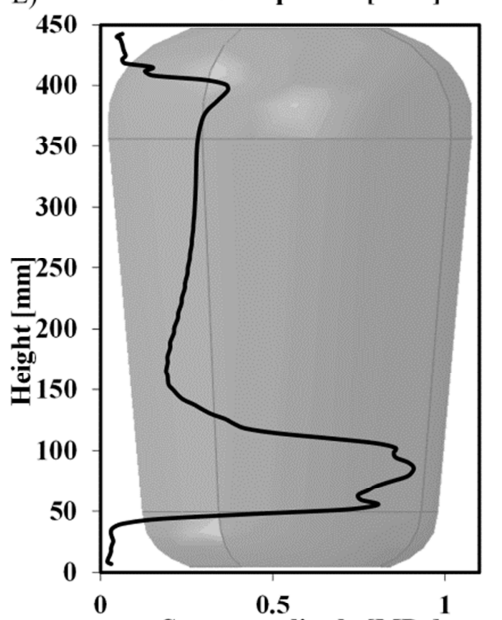

H)

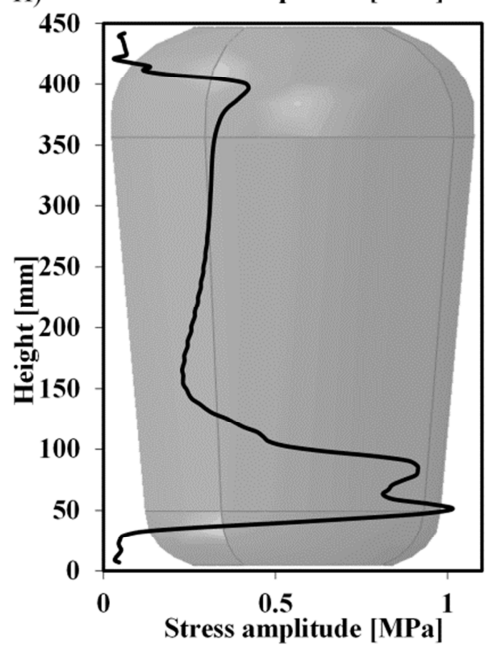

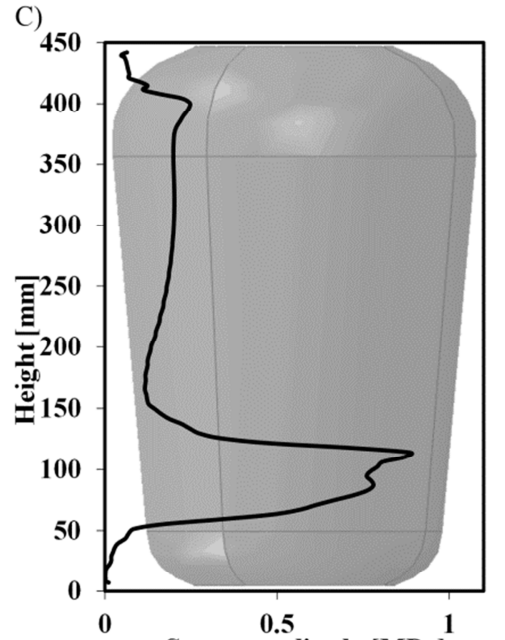

F)

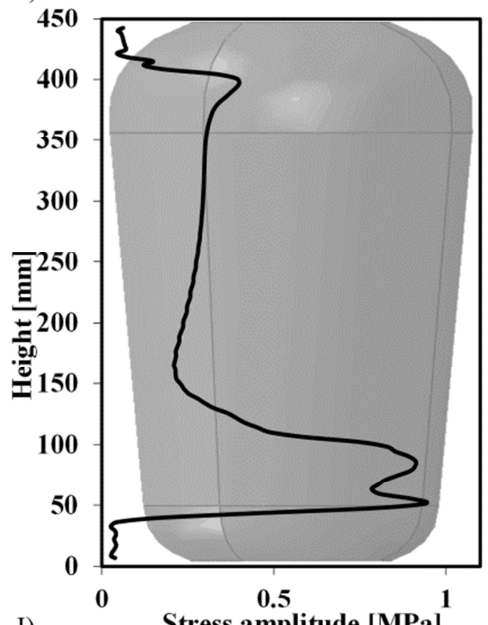

I)

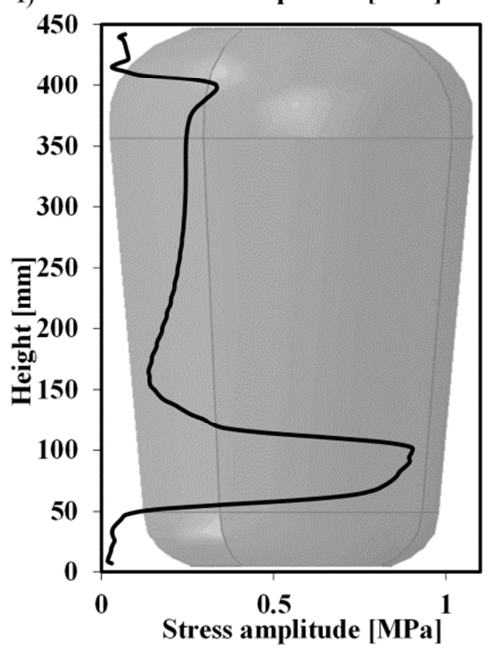



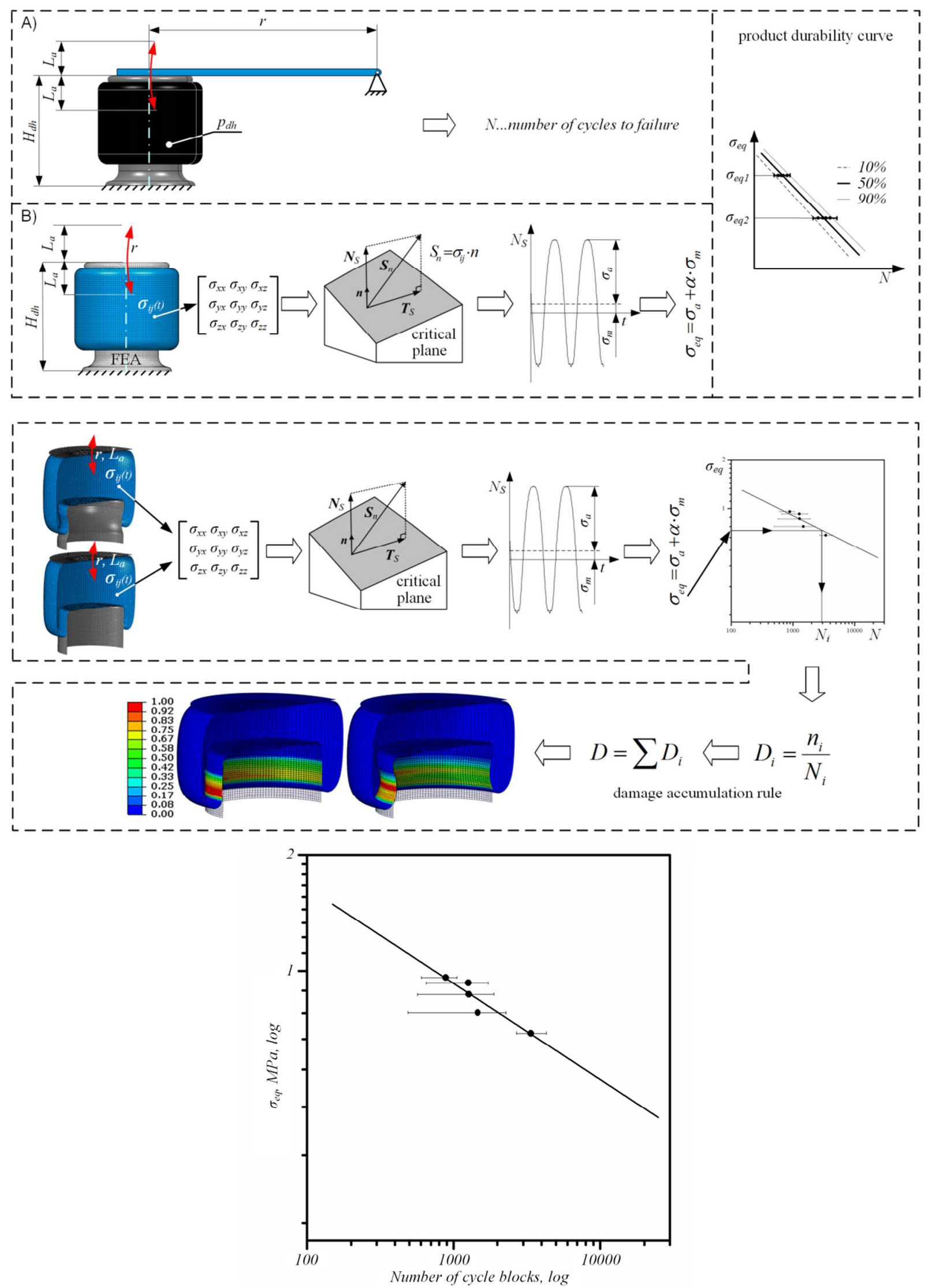

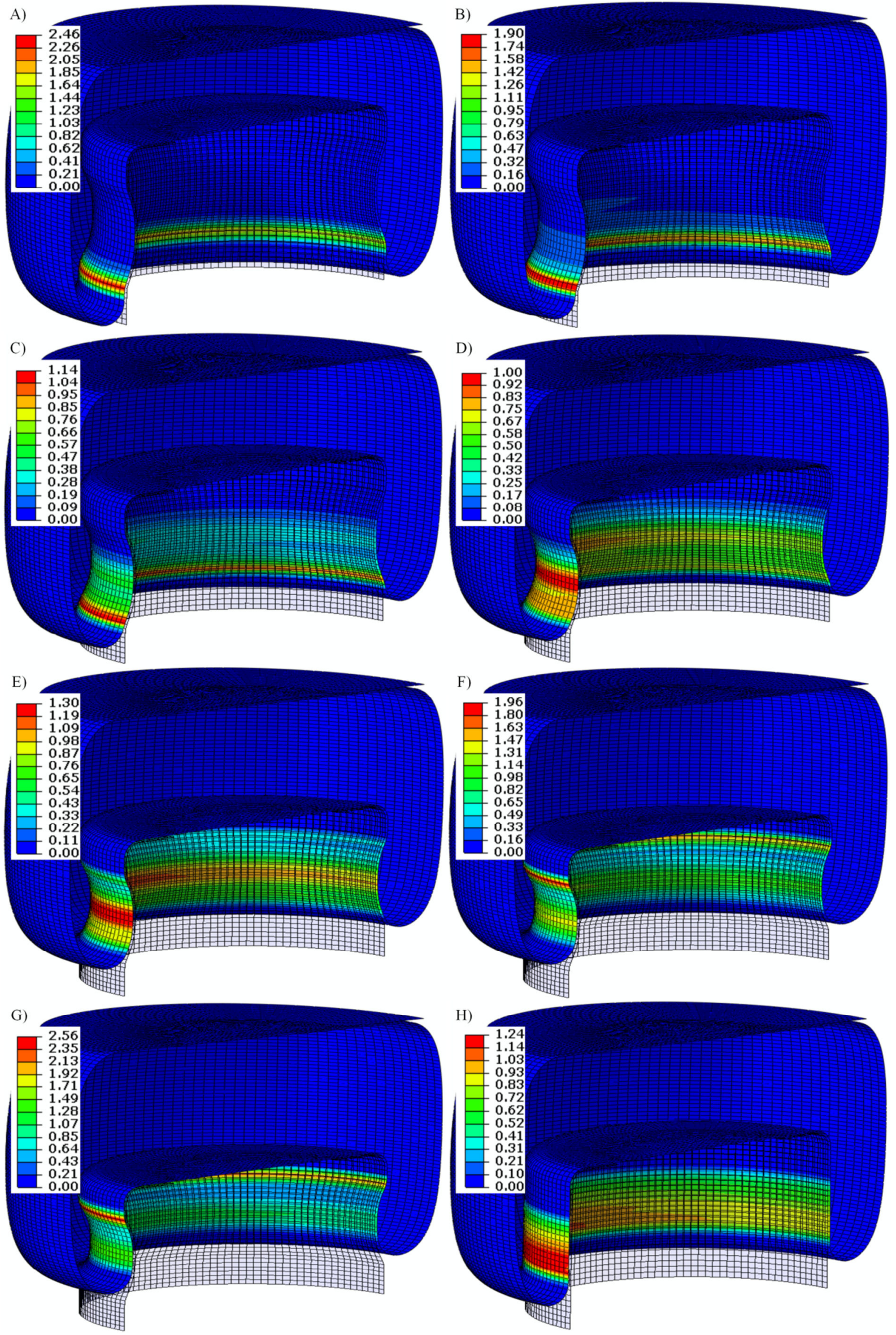


\begin{tabular}{|c|c|c|c|c|c|c|c|}
\hline \multirow[b]{2}{*}{ 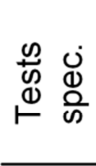 } & Test number & 1 & 2 & 3 & 4 & 5 & 6 \\
\hline & $\begin{array}{l}\text { Design height }[\mathrm{mm}] \\
\text { Load amplitude }[\mathrm{mm}] \\
\text { Pressure at } \mathrm{DH}[\mathrm{bar}]\end{array}$ & $\begin{array}{l}205.5 \\
44.5 \\
9.0\end{array}$ & $\begin{array}{l}214.4 \\
35.6 \\
9.0\end{array}$ & $\begin{array}{l}214.4 \\
50.7 \\
9.0\end{array}$ & $\begin{array}{l}205.5 \\
31.5 \\
9.0\end{array}$ & $\begin{array}{l}214.4 \\
50.7 \\
7.0\end{array}$ & $\begin{array}{l}214.4 \\
44.5 \\
9.0\end{array}$ \\
\hline \multirow{6}{*}{ 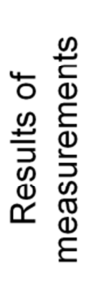 } & $\begin{array}{ll}\Phi & \text { Specimen } 1\end{array}$ & 1293 & 1530 & 608 & 494 & 3116 & 1157 \\
\hline & Specimen 2 & 942 & 733 & 870 & 2297 & 4342 & 655 \\
\hline & Specimen 3 & 1568 & 1553 & 1008 & 1769 & 2688 & 1741 \\
\hline & 음 Specimen 4 & 1527 & 918 & 1052 & 1312 & 3447 & 1508 \\
\hline & $\stackrel{\Omega}{\varrho}$ Average & 1333 & 1184 & 885 & 1468 & 3394 & 1265 \\
\hline & తे St. dev. & 287 & 420 & 200 & 764 & 694 & 472 \\
\hline \multirow{4}{*}{ 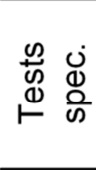 } & Test number & 1 & 2 & 3 & 4 & 5 & 6 \\
\hline & \multirow{2}{*}{$\begin{array}{l}\text { Design height }[\mathrm{mm}] \\
\text { Load amplitude }[\mathrm{mm}]\end{array}$} & 205.5 & 214.4 & 214.4 & 205.5 & 214.4 & 214.4 \\
\hline & & 44.5 & 35.6 & 50.7 & 31.5 & 50.7 & 44.5 \\
\hline & Pressure at DH [bar] & 9.0 & 9.0 & 9.0 & 9.0 & 7.0 & 9.0 \\
\hline$\frac{\dot{0}}{\mathbb{N}}$ & $\begin{array}{l}\text { Max. Equivalent } \\
\text { stress [Mpa] }\end{array}$ & 0.87 & 0.87 & 0.96 & 0.78 & 0.69 & 0.93 \\
\hline
\end{tabular}

\begin{tabular}{|c|c|c|c|c|}
\hline \multicolumn{2}{|c|}{ Case } & 1 & 2 & 3 \\
\hline \multirow{2}{*}{\multicolumn{2}{|c|}{$\begin{array}{l}\text { Design height [mm] } \\
\text { Piston shape }\end{array}$}} & 283 & 260 & 260 \\
\hline & & $\begin{array}{l}\text { Back } \\
\text { tapered }\end{array}$ & $\begin{array}{l}\text { Back } \\
\text { tapered }\end{array}$ & Straight \\
\hline \multirow{5}{*}{ 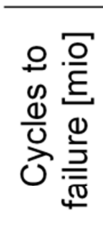 } & Specimen 1 & 1.5 & 2.7 & 2.9 \\
\hline & Specimen 2 & 1.5 & 3.9 & 2.7 \\
\hline & Specimen 3 & 1.5 & 3.0 & I \\
\hline & Average & 1.5 & 3.2 & 2.8 \\
\hline & St. dev. & 0 & 0.62 & 0.14 \\
\hline \multicolumn{2}{|c|}{ Average/Relative } & 0.47 & 1 & 0.87 \\
\hline
\end{tabular}

\begin{tabular}{clcl}
\hline Case & $\begin{array}{l}\text { Design } \\
\text { height }[\mathrm{mm}]\end{array}$ & $\begin{array}{l}\text { Piston } \\
\text { shape }\end{array}$ & $\begin{array}{l}\text { Number of cycles } \\
\text { to failure }(\mathrm{D}=1)\end{array}$ \\
\hline 1 & 230 & B. tap. & 0.406 \\
2 & 240 & B. tap. & 0.528 \\
3 & 250 & B. tap. & 0.878 \\
4 & 260 & B. tap. & 1 \\
5 & 270 & B. tap. & 0.767 \\
6 & 280 & B. tap. & 0.619 \\
7 & 283 & B. tap. & 0.510 \\
8 & 290 & B. tap. & 0.390 \\
9 & 260 & Straight & 0.805 \\
\hline
\end{tabular}

